\title{
Looking for the sun within the educational core standards: the Spanish case
}

\author{
Antonio Eff-Darwich ${ }^{1,2, *}$, Pere Ll. Pallé2,3 , and Alfred Rosenberg ${ }^{2,3}$ \\ ${ }^{1}$ Dept. of Specific Didactics, Faculty of Education, University of La Laguna, 38206, Spain \\ ${ }^{2}$ Instituto de Astrofísica de Canarias, 38206, Spain \\ ${ }^{3}$ Dept. of Astrophysics, Faculty of Science, University of La Laguna, 38206, Spain
}

\begin{abstract}
Although Astronomy is engaging and motivating for both precollege and college students, it is often difficult to fit it in within the formal educational core standards. In this work, we present an analysis of the Spanish educational curricula for primary school to look for opportunities to adapt the tools and the science behind the most famous discoveries about the sun. In this way, we attempt to find opportunities to explain concepts such as: energy, electricity, magnetism, dynamics, astronomy, data analysis, algebra, arithmetics, geometry, language and communication skills, music, cooperative working, computing, the use of new technologies and problem-based learning.
\end{abstract}

\section{Introduction}

Astronomy is one of the oldest sciences. The observation of the sky and the analysis of these observations have allowed to develop, throughout history, innumerable mathematical, methodological and technological tools. This historical importance should be reflected in the educational system of any country and, in general, educational curricula at different levels include topics such as day-night, phases of the moon, seasons, stars, planets and other structures at different scales of the universe, astrobiology, etc. There are countless didactical resources, articles and books devoted to the teaching and learning of astronomy [1]. All research institutions related to astronomy and space sciences, as well as scientific astronomical associations implement educational resources to show the impact of their scientific results [2-6]. All these resources and teaching strategies are usually adapted to the different stages of education, offering even adaptations for students with some special needs. It is worth noting that in recent years a great effort has been made not only to prepare didactical material or new methodologies for teaching astronomy, but to investigate the effect on classroom instruction, namely the student's understanding and the effectiveness of instructional methods [1].

In this work we present educational resources about the sun and its use within the Spanish educational system, particularly in primary education. From an administrative point of view, any kind of resource or concept included in the didactical programs of any school should be contained in some way in the educational curriculum. If not, they become anecdotal facts (a workshop, a talk, ...) without a clear impact on the teaching-learning process of the students. We present an educational strategy in which the sun will be used as

\footnotetext{
* Corresponding author: adarwich@ull.edu.es
} 
an educational resource for different subjects and that fit within the current curricular framework. In this way we create interdisciplinary activities where different properties of our star are used to connect subjects as diverse as music, arts, language, science, mathematics, etc. In section 2 we describe the Spanish educational system and explain why this strategy will be implemented in primary education. In section 3 we describe the strategy devised in this work and show some examples in the form of activities.

\section{The Spanish Educational System}

The Spanish educational system is divided into stages [7], corresponding approximately to a series of age ranges (see Table 1). The pre-school stage is not obligatory, starting at the age of 3 . At the age of 6 , children begin the primary education stage, which is compulsory and it is divided into 6 levels. Secondary school (the Spanish Educación Secundaria Obligatoria, ESO) is also compulsory, but the curriculum is no longer common to all students, since they have to decide during their third year of ESO where they want to continue their learning towards academic itineraries, namely science and technology, humanities and social sciences, arts or towards vocational formation (the Spanish Formación Profesional, FP). The last two years of the academic-oriented secondary education (the Spanish Bachillerato) are not compulsory, but it is the way to get access to undergraduate studies. Vocational formation is not compulsory, but they are needed to obtain the qualification for most professional works.

Table 1. Temporal distribution of the different stages of the Spanish educational system.

\begin{tabular}{|l|l|l|l|l|l|l|l|l|l|l|l|l|l|l|l|l|}
\hline & \multicolumn{10}{|c|}{ AGE (YEARS) } \\
\hline & 3 & 4 & 5 & 6 & 7 & 8 & 9 & 10 & 11 & 12 & 13 & 14 & 15 & 16 & 17 & 18 \\
\hline Pre-school & $\mathrm{x}$ & $\mathrm{x}$ & $\mathrm{x}$ & & & & & & & & & & & & & \\
\hline Primary & & & & $\mathrm{x}$ & $\mathrm{x}$ & $\mathrm{x}$ & $\mathrm{x}$ & $\mathrm{x}$ & $\mathrm{x}$ & $\mathrm{x}$ & & & & & & \\
\hline ESO 1-3 & & & & & & & & & & $\mathrm{x}$ & $\mathrm{x}$ & $\mathrm{x}$ & & & & \\
\hline ESO 4 & & & & & & & & & & & & & $\mathrm{x}$ & & & \\
\hline Bachillerato & & & & & & & & & & & & & & $\mathrm{x}$ & $\mathrm{x}$ & \\
\hline Basic FP & & & & & & & & & & & $\mathrm{x}$ & $\mathrm{x}$ & $\mathrm{x}$ & & & \\
\hline Middle FP & & & & & & & & & & & & & & $\mathrm{x}$ & $\mathrm{x}$ & \\
\hline Higher FP & & & & & & & & & & & & & & & & $\mathrm{x}$ \\
\hline
\end{tabular}

Primary school students receive 30 teaching hours each week. The distribution of these hours amongst the different subjects depends on the course the students take (see Table 2). In any case, the subjects with greater teaching load are mathematics, language and English. Each subject is organized in terms of learning blocks, where a set of contents are included. The content corresponds to the facts, concepts, data, principles, theories, formulas, as well 
as attitudes, values and norms [7]. The Spanish educational system is not based on the evaluation of the acquisition of contents, but on a series of evaluation criteria. The evaluation criteria include implicitly: mental processes expressed with infinitives (i.e. to distinguish, to measure, to relate, ...), the contents and the context (real, simulated or virtual). The evaluation criteria are measured through evaluatable learning standards which specify what the student should know and understand in each subject; they must be observable, measurable, and evaluatable. The design of the evaluatable learning standards should contribute to and facilitate the design of standardised and comparable tests. They are also the reference for the evaluation of the objectives and for the evaluation of the level of acquisition of the competences.

Table 2. Weekly distribution of lecture hours for the different courses of the Spanish primary education system.

\begin{tabular}{|l|l|l|l|l|l|l|}
\hline \multicolumn{1}{|c|}{ SUBJECT } & \multicolumn{5}{c|}{ YEAR } \\
\hline Natural Sciences & $1^{\text {st }}$ & $2^{\text {nd }}$ & $3^{\text {th }}$ & $4^{\text {th }}$ & $5^{\text {th }}$ & $6^{\text {th }}$ \\
\hline Social Sciences & 3 & 2 & 3 & 2 & 2 & 2 \\
\hline Arts & 2 & 3 & 2 & 3 & 2 & 2 \\
\hline Sports & 4 & 4 & 3 & 3 & 4 & 3 \\
\hline Language and Literature & 3 & 3 & 3 & 3 & 3 & 3 \\
\hline English & 6 & 5 & 6 & 5 & 6 & 6 \\
\hline Maths & 3 & 3 & 4 & 4 & 4 & 4 \\
\hline Religion / Social Values & 5 & 6 & 5 & 6 & 5 & 6 \\
\hline $2^{\text {nd }}$ Foreign Language & 1 & 1 & 1 & 1 & 1 & 1 \\
\hline Region-dependent subject & 2 & 2 & 2 & 2 & & \\
\hline Extra time for a subject & 1 & 1 & 1 & 1 & 1 & 1 \\
\hline Total (hours) & $\mathbf{3 0}$ & $\mathbf{3 0}$ & $\mathbf{3 0}$ & $\mathbf{3 0}$ & $\mathbf{3 0}$ & $\mathbf{3 0}$ \\
\hline
\end{tabular}

Primary Education looks as the best stage to introduce concepts related to astronomy in the curriculum, since all students share the same curriculum, before they decide amongst different academic or vocational itineraries. Primary Education students also have a high degree of motivation, curiosity and creativity that we want to preserve and even enhance with the educational strategies implemented in this work. Moreover, it is simpler to set up any kind of educational activity since the same teacher is responsible for most of the subjects. 


\section{Looking for the sun within the curriculum}

There are over 500 evaluable learning standards associated with the subjects taught in the Spanish primary education system. The term 'sun' appears only once in that list, hence the contents associated with the study of our star are very poor. For this reason, and in order to increase the weight of a resource like the sun in primary education, we have developed a simple methodology: we will use the sun as a didactic resource associated with the learning standards of different subjects. We will not learn directly about the sun, but will use properties of our star as a didactic resource in practically all the subjects of this educational stage.

To find out what standards are related to the sun, we made a list of keywords that define properties of the star, namely: sun, circle, music, circumference, geometric, energy, atom, electricity, magnetism, magnet, convection, nuclear, fission, star, instrumentation, gravity, force, universe, plasma, temperature, heat, ellipse, musical, molecule, atmosphere, report, distance, angle, density, mass, motion, balance, game and presentation. The learning standards associated with these keywords are now 50 (recalling that 'sun' is only found once in the learning standards list) and cover all primary education subjects and all courses. The sun is now a resource for engaging, evaluating, explaining ... in subjects as varied as mathematics, physical education or science, thus reinforcing the interdisciplinary character of education and knowledge in general.

To illustrate the strategy we have designed, two activities associated with learning standards of arts (music and drawing) will be described. Activities for other areas are under development and implementation. The activity associated with the area of music is devoted to reinforcing the intimate relationship between music and feelings. A video without sound about the magnetic activity on the surface of the sun (see Fig. 1) is presented to the students. The teacher explains (adapting to the age of the students) the set of phenomena that can be distinguished in the images (rotation, magnetic field lines, flares, etc ...). Obviously, this type of content is not usually included in educational curricula. However, in our case, the explanation of what we are seeing facilitates the description of the feelings that the video produces (fear, curiosity, suspense, admiration, ...). Next, the teacher will ask them (individually, in collaborative groups, or as the teacher considers) to look for a song that describes those feelings. We are evaluating standards of music learning through the study of physical phenomena that occur on the surface of the sun, concepts that would otherwise have no place in the programming of schools.

A second activity where we will use the sun as a resource to evaluate learning standards of arts consists on creating a color palette. The colours will correspond to the color indices of the stars (see Table 3). The color of stars depends largely on their surface temperature. In the case of the sun, its surface temperature implies that its color looks white. Once the color-temperature relationship for the stars is shown, the teacher will ask the students to draw and color a landscape using only the colours of the palette we have described. Once again we are providing information about the sun (and other stars) based on learning standards from other subjects, in this case, art. 


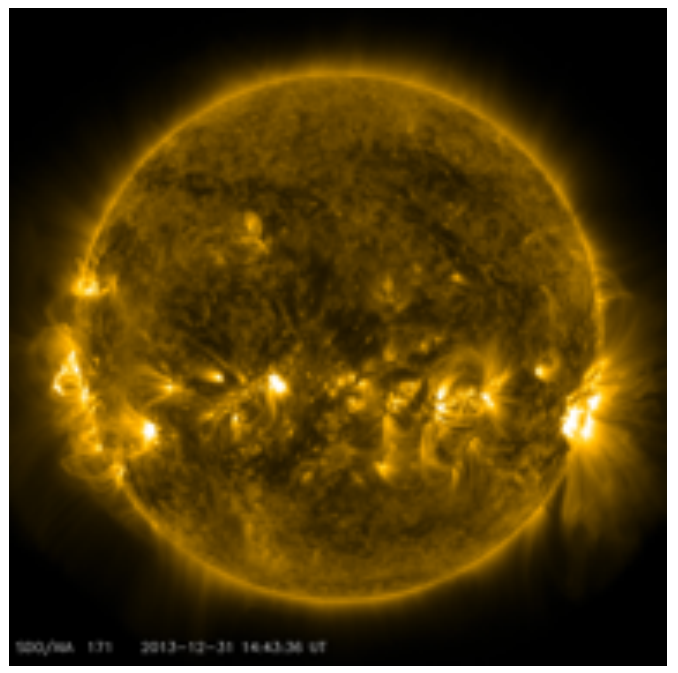

Fig. 1. Frame from a video showing the magnetic activity of the sun. Courtesy NASA/SDO

It is not the purpose of this work to define in detail the activities and resources that are being developed, but to emphasize the idea that it is possible to evaluate the learning standards of different subjects through a resource, such as the sun, which otherwise would not have a place so simple and direct in the Spanish system of primary education.

Table 3. Definition of stellar classes as a function of surface temperature. Cell colours correspond to the actual colours of the stars.

\begin{tabular}{|c|c|}
\hline STELLAR CLASS & TEMPERATURE $(\mathrm{K})$ \\
\hline O & $>33000$ \\
\hline B & $10000-30000$ \\
\hline A & $7500-10000$ \\
\hline F & $6000-7500$ \\
\hline G & $5200-6000$ \\
\hline K & $3700-5200$ \\
\hline M & $<3700$ \\
\hline
\end{tabular}

All these activities are part of a more global strategy of the teaching-learning process on science and the scientific method that we are developing and which consists of: 
i) To increase the number of activities outside the classroom, in particular the use of the school playgrounds (see Fig. 2).

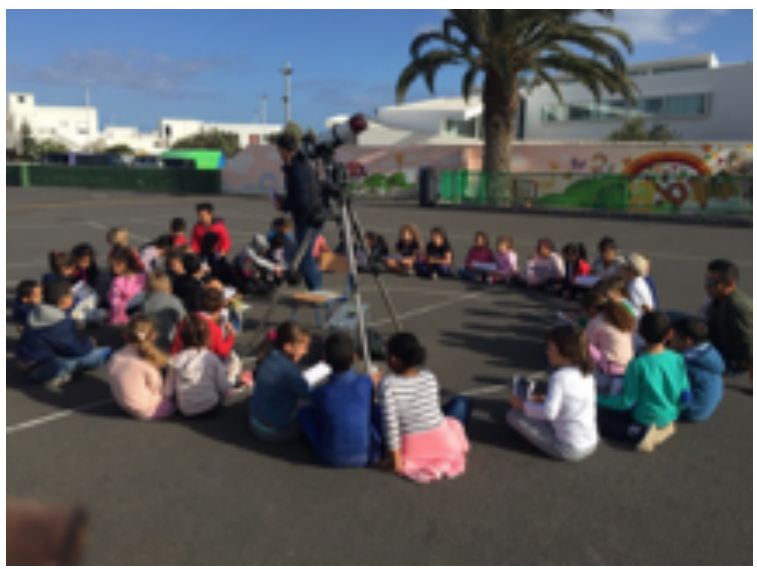

Fig. 2. Observation of the sun with a solar telescope at the playground of a primary school in the island of Lanzarote, Canary Islands (Spain). Courtesy of the Martianos Project [8].

ii) To actively involve families in the education of the students (see Fig. 3), making them participants in some curricular activities.

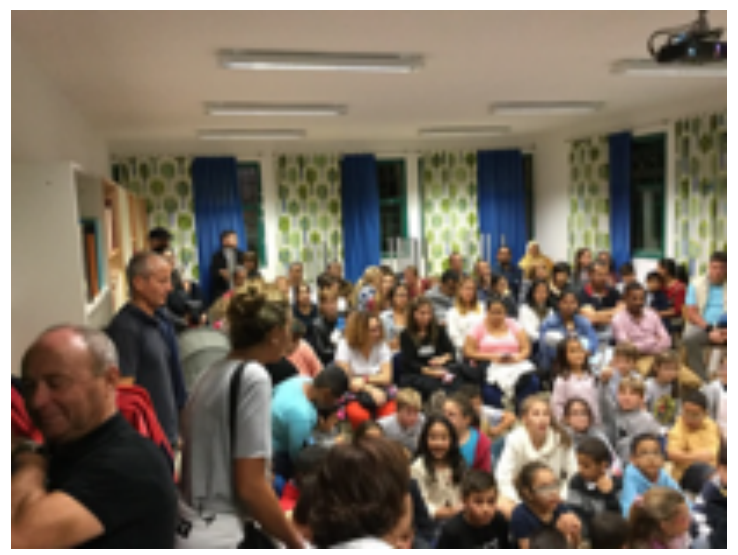

Fig. 3. A group of parents attend a talk about the sun with their children. Courtesy of the Martianos Project.

iii) Use of simple didactic materials that draw the student's attention and which they can manipulate (see Fig. 4). We attempt to enhance children's curiosity about everyday natural phenomena that usually go unnoticed. In this way, we try to improve the capacity of observation and analysis of primary school students. 


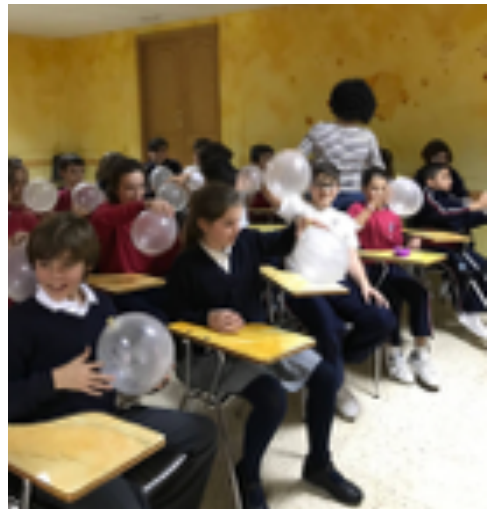

Fig. 4. A group of primary school students play around with balloons that represent the solar system.

iv) To show undergraduate students of the faculties of education that science is not an isolated knowledge, and that it is part of the culture of a society. In this sense, teachers should be able to teach about science and the nature of science using resources associated with other cultural forms, such as theater, dance (see Fig. 5), music, literature, etc ...
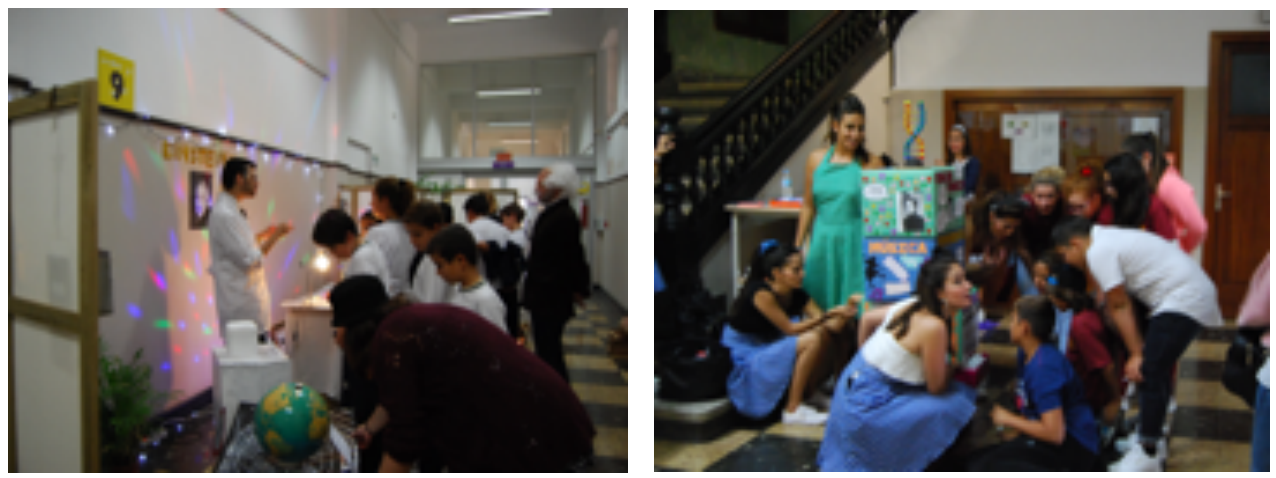

Fig. 5. A group of undergraduate students from the Faculty of Education of the Universidad de La Laguna (Spain) explain the basics of the theory of relativity to primary school students (left image). Right image shows a different group of undergraduate students explaining the basics of the structure of DNA through music and dance.

\section{Conclusions}

In this work we introduced a simple strategy with which we can increase the number of hours dedicated to show contents about the sun in the didactic programs of Spanish primary schools. This is achieved by using the sun as a resource to evaluate learning standards of different subjects. In this way, we also stress out the interdisciplinary nature of the teachinglearning processes in primary education. Two activities are presented in which we connect music and drawing with the study of the sun, through the search for evaluatable learning standards. Similar activities for other subjects in which we use the sun as a resource are under development. 


\section{References}

1. J. Bailey, T. Slater, The Astronomy Education Review 2, 20 (2004)

2. http://astroedu.iau.org/

3. http://solar-center.stanford.edu/teachers/

4. http://suntrek.org/

5. http://nasawavelength.org/

6. http://www.esa.int/Education/Classroom_resources

7. Spanish Primary Education Curriculum, http://www.gobiernodecanarias.org/ educacion/web/primaria/informacion/contenidos/

8. http://www3.gobiernodecanarias.org/medusa/proyecto/35700043-0005/ 